\title{
A STARRY STARRY NIGHT: LEARNINGS FROM A MULTICULTURAL MATARIKI DINNER HOSTED BY A COHORT OF INTERNATIONAL STUDENTS
}

Roz Tocker

\section{INTRODUCTION}

Over several years of teaching mostly international students in hospitality programmes, it has become increasingly apparent that most struggle with concepts of tikanga Māori (customary values and practices) in the classroom. Furthermore, a great many intend to make Aotearoa New Zealand their home and, as educators, it seems morally incumbent on us to help them understand the unique dual heritage and culture into which they will be settling. International students arrive having their own set of values, but we need to enable those students to absorb our morals and ethics, too, to be truly exposed to them, and to understand that all cultural values have synergy: they can overlap. Butcher and McGrath (2004) point out that often international students will arrive in a new setting with a myriad of complex predicaments and expectations. These may include language and financial issues and an awareness that, somehow, they need to become assimilated into a society which is sometimes discriminatory.

This article describes how, through a Matariki dinner/banquet, a large group of Level 4 international food and beverage students at Toi Ohomai Institute of Technology were taught, and learnt, about the Māori cultural values of the institution. The initiative has led to epiphanies for both teacher and students, and has completely changed my own teaching pedagogy.

\section{BEING NON-MĀORI}

As a non-Māori academic staff member, I strive to live bicultural values within our own Toi Ohomai principles:

Whanaungatanga - we build and nurture relationships and connections; Toitūtanga - we are humble in our pursuit of excellence; Kotahitanga - we are united towards our shared purpose and lastly Manaakitanga - we uphold and strengthen the mana of others and our communities (Toi Ohomai Institute of Technology, 2021, Our values section).

While I am learning new ways to think and feel in my professional role, I can understand a little of how international students must feel, encountering a whole new realm of often tacit knowledge. My starting point with this project came from questioning how, as their teachers, we can create an environment where the students can know, understand and experience these cultural values. This made me aware of what Larrivee (2000) argues, that educators should evaluate their expectations in order to deliver a more meaningful learning experience. This was therefore an opportunity for me, too, to reassess my teaching methods in order to embrace a multicultural classroom. In a food and beverage training context, I framed this from a teaching and learning perspective as: "We need to understand who we are as people, how we grow our food, and how close we are to the source and our sense of manaakitanga or hospitality" (Clifford, 2018). 


\section{THE MATARIKI CELEBRATION}

Matariki heralds the Māori New Year and is seen as a time of reflection and celebration. It has become a significant event on the lunar and social calendar and, from Friday 24 June 2022, it will be celebrated as a public holiday. According to Hardy and Whaanga (2019), most Māori understand that the Matariki celebration is associated with the indigenous knowledge of the departmental gods, the children of Ranginui (sky father) and Papatuannuku (earth mother). They also celebrate with elements including fire and water, and with various forms of food cultivation and gathering. Furthermore, food which corresponds to each star is cooked and a karakia (prayer) is offered to the stars to ensure nourishment. Hardy and Whaanga (2019) further suggest that by celebrating these practices, Māori are "reinvigorating the principles of whakapapa" and incorporating "the link between deities, the environment, animals and the activities of human beings" (p. 8).

In light of these traditions, it was equally important that our Toi Ohomai Matariki menu was aligned to the significance of the stars. This resulted in significant collaboration between chefs, students, tutors and our Māori academic team.

Following a number of discussions with the strategic partnership team, I developed the concept of a degustation dinner in Kaiwhata (our Mokoia (Rotorua) campus training restaurant) to celebrate Matariki. As part of the student learning experience, the restaurant is open to the public, stakeholders and fellow students several times a semester. This opportunity gives hospitality students a realistic, hands-on experience. However, this dinner was in a different league from what students would normally experience, so it really put them to the test. Because this event required significant student involvement, it showcased biculturalism and multiculturalism as well as innovation, and incorporated all of Toi Ohomai's values.

Meeting the responsibilities inherent in these values was a major undertaking, so I adopted a whakataukT (Māori proverb) to guide me through the degustation project: "Whāia te iti kahurangi ki te tūohu koe me he maunga teitei" (Woodward, 2020): "Seek the treasure you value most dearly and if you bow your head, let it be to a lofty mountain." The message of this whakataukT is to be persistent and not to let obstacles stop you from reaching your goal. One of the perceived obstacles when developing the Matariki initiative was that I had a multicultural class of students (one Māori/Niuean, four Nepalese, one Malaysian and ten Indian students) with limited understanding of te ao Māori (Māori worldview). As these students would be instrumental in delivering and hosting the event, and would need some background knowledge of biculturalism, I approached our Māori academic team, who offered me invaluable support in providing information sessions with the students and tutors about the cultural relevance of the Matariki constellation.

In 2019 Matariki reappeared in the dawn sky between 25 and 28 June, signalling the start of the Māori New Year. I wanted to celebrate this by helping create a new or different life for our students, while keeping in mind those who had passed (as in any family or culture) and planning a new future full of knowledge and good health. I endeavoured to create a whānau atmosphere of trust and guidance, while enjoying kai (food), waiata (song) and tākaro (games).

With all this in mind, from mid-April I began planning a dinner event to take place on Thursday 27 June 2019. After some research on the Matariki star cluster, I decided that the dinner theme would take the form of nine courses, each representing a star. I then spoke with some of the culinary arts staff to ascertain their interest in the event. Two chef tutors were enthusiastic and, after discussions with a Māori academic advisor, I left them to create authentic dishes for a menu suited to the occasion.

Figures I and 2 show the dishes conceived for the menu, each aligned with a star in the Matariki cluster, and the menu flyer created for the event. 
Matariki

Pōhutukawa
Matariki is the star that signifies reflection, hope, our connection to the environment and the gathering of people. Matariki is also connected to the health and wellbeing of people.
Kawakawa shot and wild herb salad - a healthy start for the dishes to come
Pohutukawa is the star connected to those who have passed on.
Venison, wild mushroom and grilled pikopiko open pie
WaitT
WaitT is connected with all freshwater bodies and the food sources that are sustained by those waters.
Smoked eel, watercress jelly and koura foam - tuna (eel), watercress and koura (freshwater crayfish) (all found in lakes, rivers and streams)
Waitā

Waipuna-ā-Rangi
Waitā is associated with the ocean and the food sources within it.
Hapuku, oysters, kina glaze with sea kelp (all from the ocean)
Waipuna-ā-Rangi is connected with the rain.
Persimmon sherbet (ice crystals from the fruit floating on dry ice)
Tupuānuku
Tupuānuku is the star connected with everything that grows within the soil to be harvested or gathered for food.
Taewa, kumara and yams with cricket and wild berries (all from the soil, berries fallen from the tree)

\begin{tabular}{|c|c|c|}
\hline Tupuārangi & $\begin{array}{l}\text { Tupuārangi is connected with } \\
\text { everything that grows in the trees: } \\
\text { fruits, berries and birds. }\end{array}$ & $\begin{array}{l}\text { Confit muttonbird with tricolour } \\
\text { kumara, cherry salsa on toasted } \\
\text { rewana (tîtī-traditionally } \\
\text { harvested sooty shearwater bird) }\end{array}$ \\
\hline Ururangi & $\begin{array}{l}\text { Ururangi is the star connected with } \\
\text { the winds. }\end{array}$ & $\begin{array}{l}\text { Fried bread pocket with pulled } \\
\text { pork, coleslaw, apple chutney and } \\
\text { watercress mayonnaise (light and } \\
\text { airy) }\end{array}$ \\
\hline Hiwaiterangi & $\begin{array}{l}\text { Hiwaiterangi is the star connected } \\
\text { with granting our wishes and realising } \\
\text { our aspirations for the coming year. }\end{array}$ & $\begin{array}{l}\text { Steamed pudding on chocolate soil, } \\
\text { vanilla cream anglaise spheres, } \\
\text { kawakawa cream and buttermilk } \\
\text { gelato (traditional pudding; spheres } \\
\text { are aspirations, gelato a treat) }\end{array}$ \\
\hline
\end{tabular}

Figure I. The menu items aligned to the nine Matariki stars. Source: Toi Ohomai Institute of Technology Marketing Department 


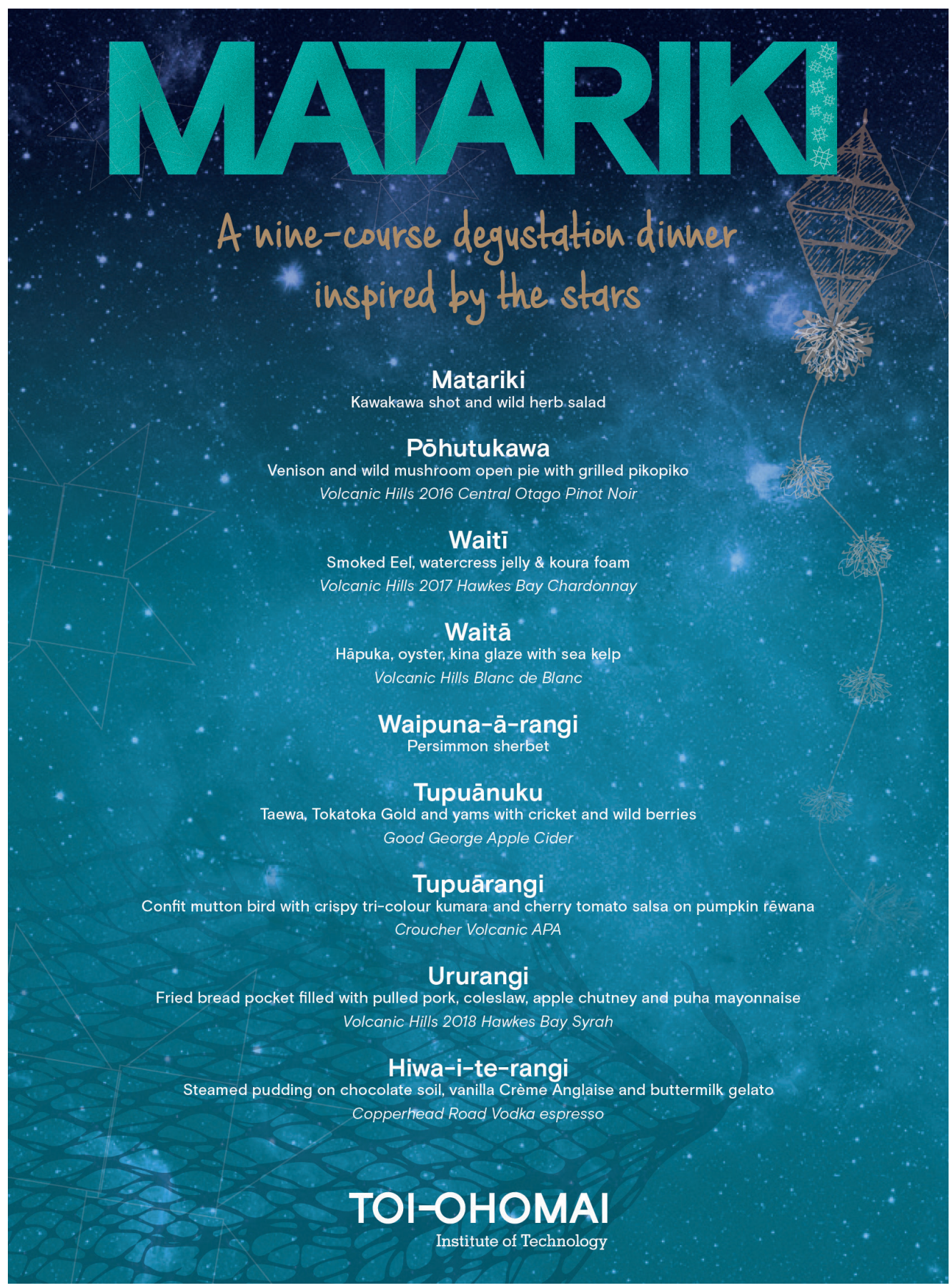

Figure 2. The menu flyer. Source: Toi Ohomai Institute of Technology Marketing Department 


\section{PLANNING AND DELIVERING THROUGH COLLABORATION}

The concept for the dinner was to have nine round tables to represent the nine stars of Matariki, with each of the nine courses incorporating ingredients that would represent the significance of each star. Several departments collaborated to make the night a success. The culinary arts team were joined by students from our hospitality courses, who hosted a full dinner service, matching alcoholic beverages with each dish; the carpentry students made the round table tops for the dinner; electrical students provided a starry lighting spectacle; the music department provided waiata; design students created nine handcrafted star lanterns to go above each table; facilities shaped wooden serving platters; marketing provided advertising and menu design; and Māori academic staff conducted information sessions with students and tutors.

Significantly, this level of participation consolidated all our institutional values and culminated in an amazing cultural achievement, with diners enjoying the relaxed atmosphere and innovative dishes. The students were buoyed by the experience, and the confidence they gained was immeasurable. As a result of this event, students realised the value of food as a universal means of bringing people together and understanding culture through food. They learnt the significance of indigenous Māori foods and the concept of food sovereignty and compared their own regional foods with what was on offer. Importantly, they learnt first-hand the value of toitutanga - to be humble in their learning in order to pursue excellence by successfully delivering kai hakari (dinner/banquet).

The values of whanaungatanga (build and nurture relationships and connections), kotahitanga (united toward a shared purpose), and manaakitanga (strengthen the mana of others and our communities) were further evidenced through the preparation for the dinner. Students and tutors stood alongside each other to give help, support and commitment. Firstly, it was important to support student learning about Māori cultural ideals - specifically, to identify the star cluster that envelopes Matariki. While students may have heard of the Pleiades, the focus on Matariki was to proceed from mātauranga Māori (a Māori perspective). Thus, I had introduced the students to a Māori academic tutor who, over a series of classes, taught them the significance of the stars and our own organisation's values (see Figure 3). As a result, in of one of these classes we unilaterally decided that the students would korero (talk through) the menu and describe the content and cultural significance of each course to diners on the night. The process of discussion or korero ensured that the students' voices were captured - adding richness to the cultural aspect of the event, upholding the value of manaakitanga and giving mana to the students involved. In addition, I created cue cards for the students so they would be reassured in what would be a time of apprehension for them - talking in English about te ao Māori in front of 50 paying guests. 


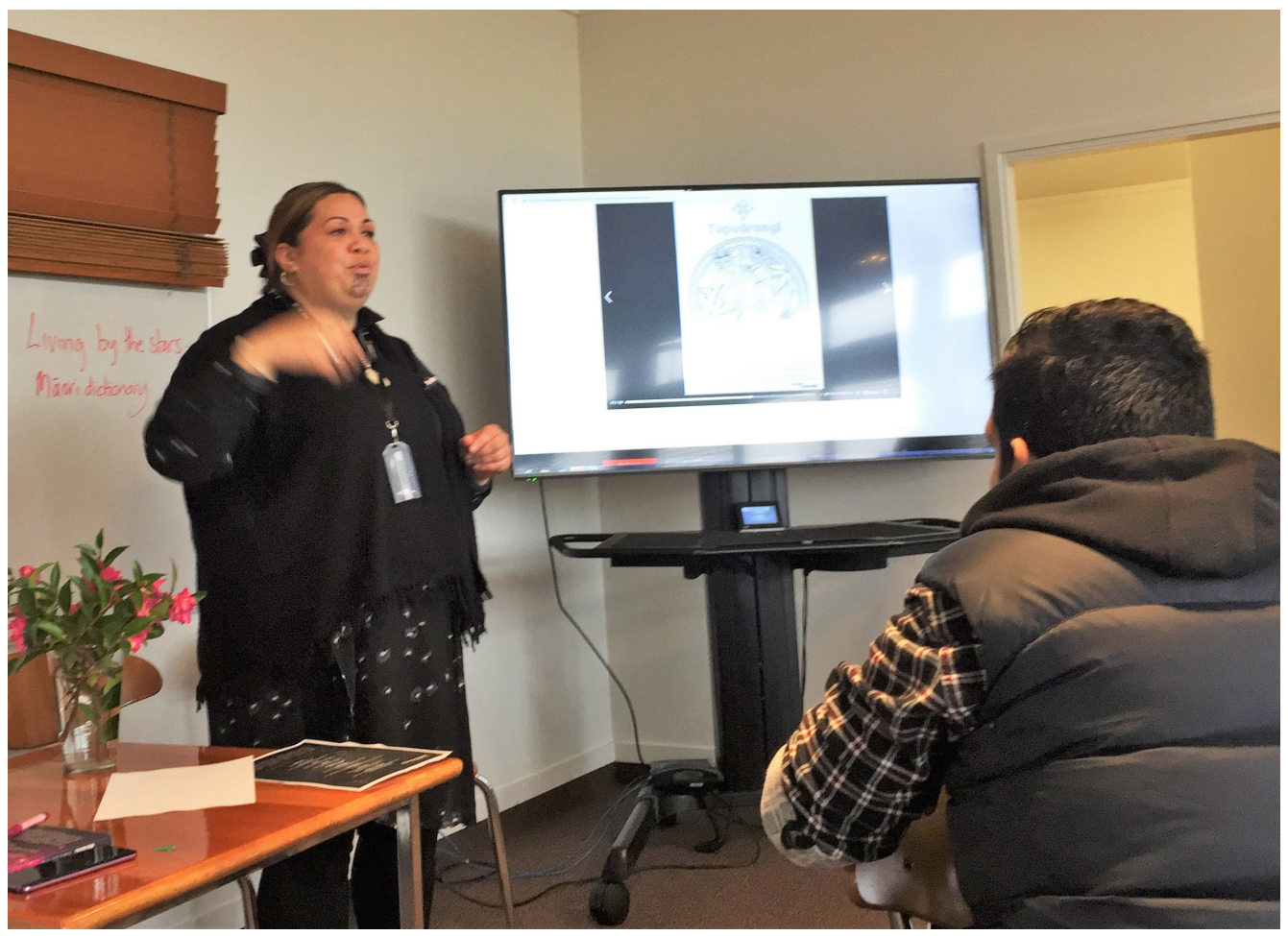

Figure 3. Māori academic advisor teaching the students about Matariki. Source: Author

In the lead-up to the dinner all the students became very involved in the preparation of the ingredients and other materials required for the event. They helped gather kawakawa (for the Matariki dish and garnish), seaweed for the Waita course and fern fronds for garnish; they glazed and polished newly made platters so they were food-ready; they made the flax napkin rings; they hung lanterns; they polished cutlery and glassware. Students were divided into two groups according to their roles as service or beverage waiters. There were a myriad of logistical elements to be considered in the presentation of the dinner, notwithstanding the plan of nine food courses matched with nine beverage courses. The students were instrumental in devising systems and service styles - in doing so, we developed a great deal of respect for one another which created a tight bond between us all. This modelled a strong example of whanaungatanga for everyone involved (Figures 4-7). 


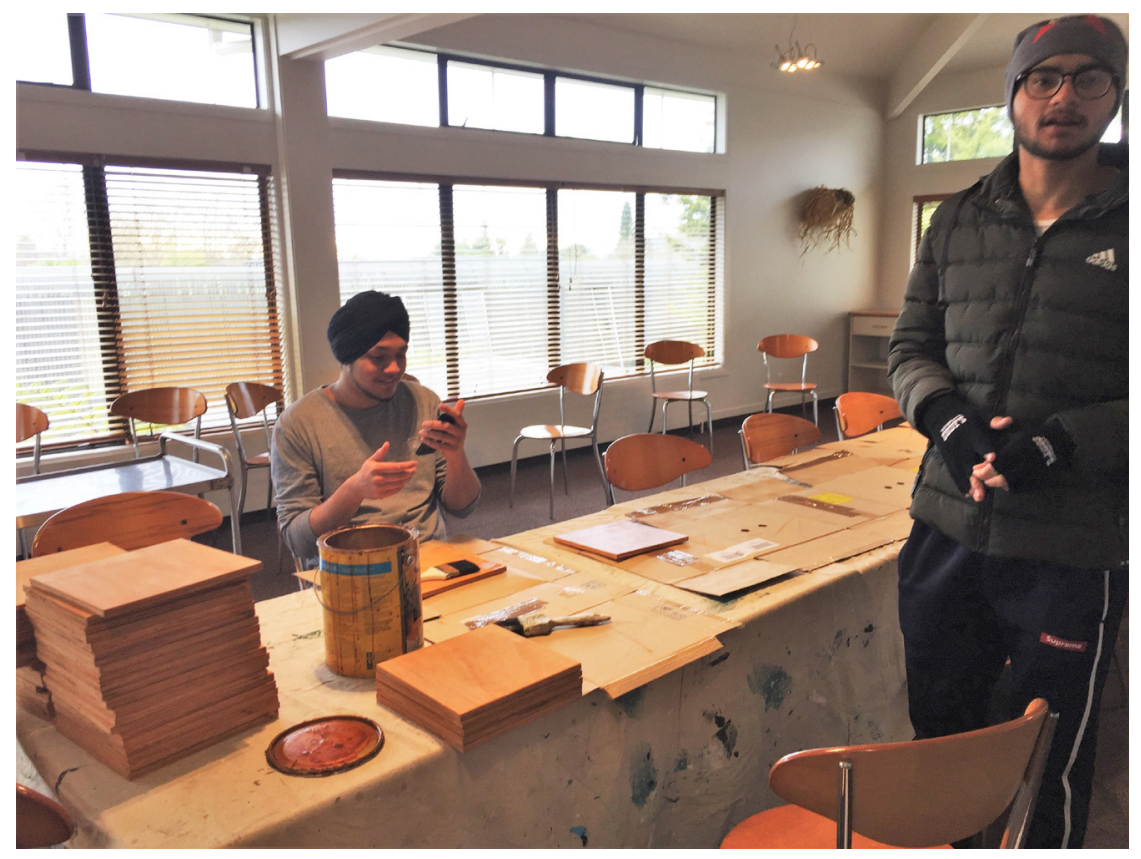

Figure 4. Students making serving platters. Source: Author

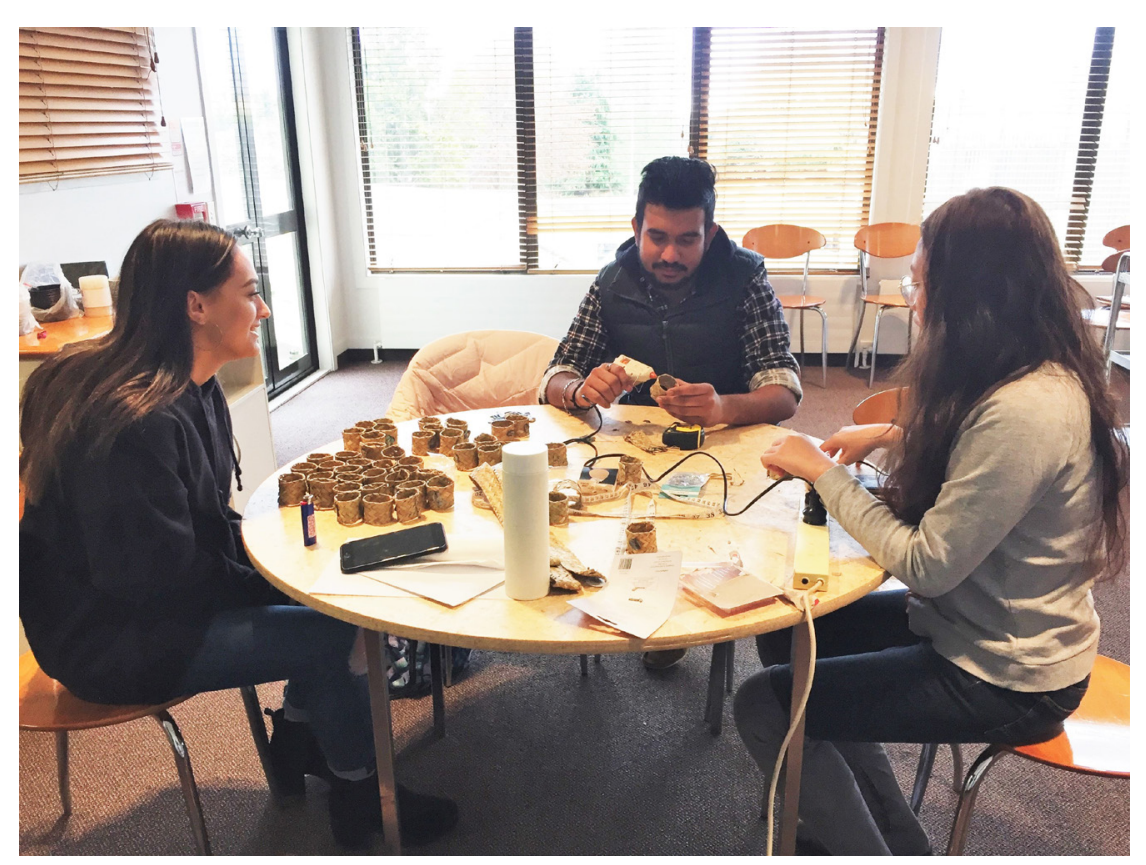

Figure 5. Students making napkin rings. Source: Author 


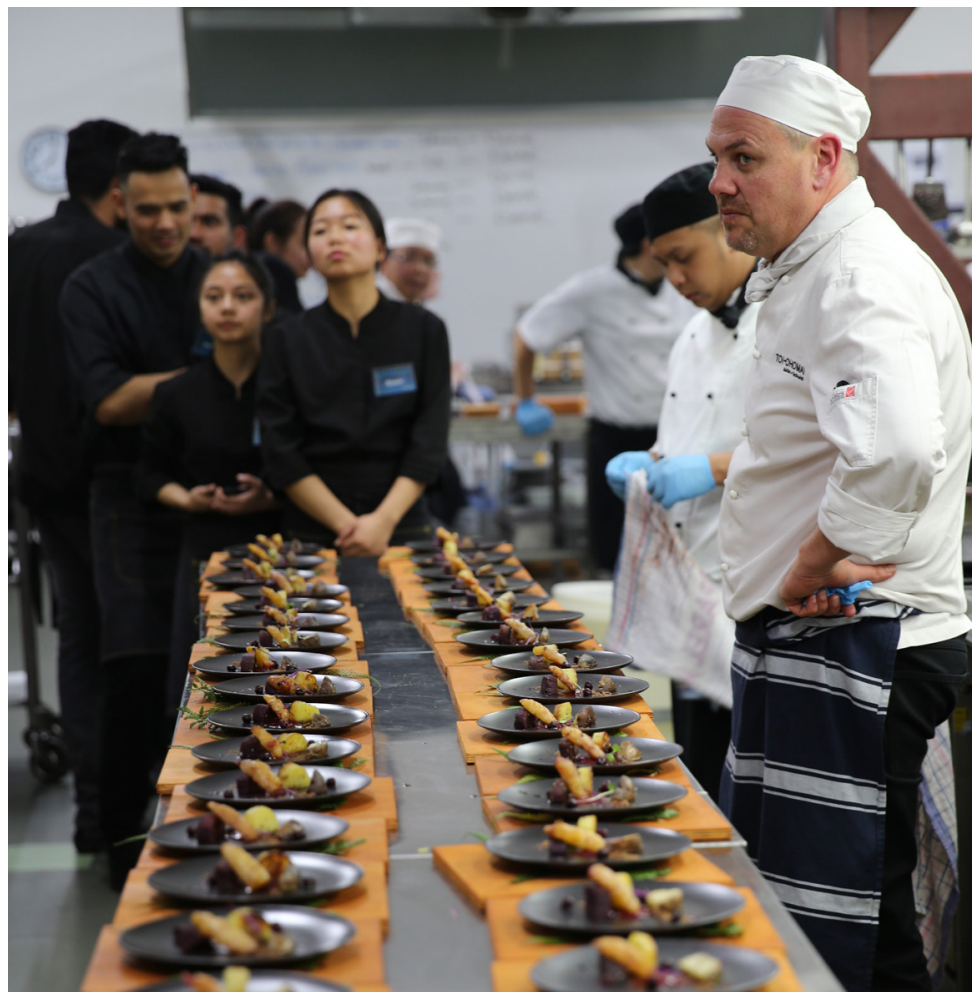

Figure 6. Students lining up for service. Source: Toi Ohomai Institute of Technology Marketing Department

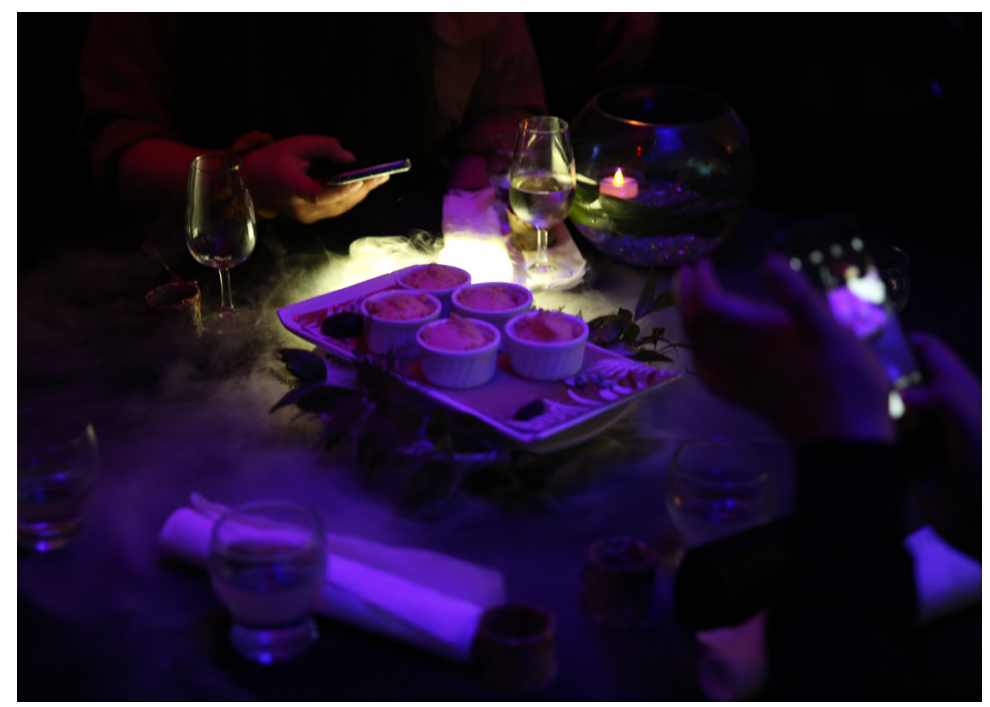

Figure 7. Waipuna-ā-Rangi. Source: Toi Ohomai Institute of Technology Marketing Department 
Following the dinner, we received some wonderful feedback from colleagues who attended the event, which I shared with the students. Representative comments included:

I especially loved that Matariki became a wonderful, meaningful, practical and memorable experience of learning for staff, students and diners!

Thank you for letting me be a small part of this Matariki event; I sincerely hope that a Matariki-inspired dinner at Toi Ohomai becomes an annual event.

I would like to acknowledge all the extra time and effort that you put into the recent extremely successful Matariki Degustation Dinner. All the behind-the-scenes work that create the magic but sometimes get overlooked in the accolades. The seaweed you gathered and dried, the wood you stained and oiled, the flowers you picked, the buzz you generated. I believe that this one event embodied all four of our Toi Ohomai Values.

\section{DISCUSSION}

The four stages of Kolb's (1984) experiential cycle - concrete experience, reflective observation, abstract conceptualisation and active experimentation - provided the fundamental framework for the development and delivery of the Matariki dinner. Didactic components were delivered in class during the four weeks prior to the event, culminating in the presentation of the dinner itself (concrete experience). Within this timeframe, the students were constantly reflecting and observing each other, coming up with improved approaches and systems as they explored both active experimentation and abstract conceptualisation.

The dinner was an opportunity for students to learn through doing, rather than being prepared by tutors to undertake an activity. Bolton (2010, p. 29) argues that this form of reflective practice also "allows relationships with students, clients, patients or colleagues to be seen within a range of possible roles. The whole person of the professional relates to the whole client." This meant that the students undertook roles that put them in the place of clients, learners, teachers and role models, a situation which they adapted to very well. Creating work-based scenarios within the learning environment was of benefit not only to me, but also to my learners.

According to Rogers (1969), learning is enhanced when the learner takes ownership of their own learning. Furthermore, "the goal of education, if we are to survive, is the facilitation of change and learning. The only person who is educated is the person who has learned how to learn; the person who has learned how to adapt and change" (Rogers, 1969, p. 152). We teach our students the basics of customer service - such as good personal presentation and open communication - but in the real world, we need systems. It was at this point that my students taught me. In Māori pedagogy this is referred to as "ako" - ako reinforces the symbiotic relationship between teacher and learner through learning together - the teacher is the learner; the learner is the teacher. It was a wonderful experience being on the same level and learning from my students as they were learning from me. The event was indicative of this process. The students were disciplined, enthusiastic and wanted to try hard. And the best part was that we exemplified at first hand Carl Rogers' theory that if the teacher values and demonstrates how the student thinks and feels, then valuable learning takes place (Rogers, 1983).

This experience opened my eyes, not only to different cultures of the world, but to our own indigenous culture. The Matariki dinner demonstrated that learning is transferable from student to teacher and vice versa. Johnson (2012) explains:

Teaching is far more complicated than simply delivering content, and learning is far more complicated than simply receiving it. Viewed through using an ecological lens, the teacher-student relationship is symbiotic. Teachers and students have a mutually beneficial relationship; each supports the other's existence. (para. 5) 
This also underscores the Māori concept of tuakana-teina, which provides a model for buddy systems.

"An older or more expert tuakana (brother, sister or cousin) helps and guides a younger or less expert teina (originally a younger sibling or cousin of the same gender). In Māori pedagogy, if tuakana-teina is conducted with aroha and manaakitanga then the mana is strengthened and all participants are rewarded"

(Winitana, 2012).

In a learning environment that recognises the value of ako, the tuakana-teina roles may be reversed at any time (Te Kete Ipurangi, n.d.).

\section{REFLECTING ON MY OWN TEACHING PRACTICE}

As a critical reflection on my own teaching practice, giving students a surrogate workplace initiative to help non-New Zealand students to understand our bicultural heritage through the Matariki degustation experience was a success. I felt that using Māori mythology to support international students learning about te ao Māori had been inspiring for all involved.

This experience has enabled me to recognise trust, respect for my own beliefs and integrity, personal responsibility and generosity through personal development and a positive regard for future actions (Bolton, 20I0). Further to this, my own experience has given me a greater insight into accommodating the physical, psychological and financial needs and cultural diversity of students. Speaking as a teacher, empathy with students is a valuable asset in teaching pedagogy, as it helps us understand student needs and wants and allows the students to feel valued and thus more inclined to learn (Rogers, 1983).

In the planning stages of the dinner, I had very little student feedback or involvement as the students relied on me as the tutor to give them the information required to organise the event. However, two days before the event, and after much cajoling, the students felt comfortable enough to give me their feedback on how the event could be run and how we could better deliver the meals, and indeed the whole experience. I feel at that stage that I had also discovered a degree of leadership within myself, in that I was so focussed on the successful outcome of the event that I drew the students into my commitment, which in turn enabled them to offer me support (Bennis, 1976). This encouragement led to a focussed approach at the final dinner and gave the students a level of confidence that was not evident earlier.

On a personal level, I feel that I am a good listener. As Helyer (20I5) advocates, "One of the most important things that tutors of work-based learners can do is develop good listening skills. They need to listen and also to respond appropriately. This response might include prompts and encouragement rather than instructions" (Helyer, 2015, p. 22). Hence the reason for the prompt cards. Understanding other people's needs, as well as being responsible, enthusiastic, friendly, patient and helpful, are important teaching attributes, and are elements that I try to weave into my own teaching philosophy.

Naturally, it helped that I was delivering a service that I was passionate about and that I also had the knowledge to enable me to upskill the students. I was able to debunk the theory that "education expertise and knowledge has been predicated on a separation of learning from working" (Vaughan, 2012, p. 4). Vaughan continues: "workplacebased education is therefore held responsible for practice (situated and tacit knowledge), as well as socialising people, inculcating them into work-related knowledge and skill and incorporating them into a community of practice" (p. 5). The Matariki degustation menu experience was an excellent opportunity to do exactly this, and to reunify the learning and working paradigm. 


\section{CONCLUSION}

As a teacher, it is always rewarding to successfully pass on knowledge for others to make discoveries. This article has outlined one initiative in which interdisciplinary expertise and competency created a platform for indigenous knowledge to be shared with international students and our surrounding community. The concept of an inspirational whakataukT, and Māori mythology as a design for delivery, is not new, nor restricted to any particular educational or vocational discipline. I hope that others may find something in the narrative offered here to be a useful departure point for their own journey towards bicultural learning, whether personal or in the classroom, and whether their learners are domestic or international. According to Andresen, Boud and Cohen (2005), a participative, learner-centred approach based on personal experience enriches learning events. This was certainly true of my experience with the Matariki degustation dinner. However, parallel to this, I credit the awhi (support) and connections with my colleagues for the event's success. We do not go on this journey alone and, together, we can overcome most obstacles:

Whāia te iti kahurangi ki te tūohu koe me he maunga teitei!

Roz Tocker is a senior lecturer in tourism and hospitality at the Mokoia campus of Toi Ohomai Institute of Technology. Prior to teaching, her experience covered many aspects of hospitality, as she had owned and operated several successful restaurants and hotels. Roz has a strong interest in gastronomic tourism and hopes to impart her enthusiasm for this subject to her students. She is currently studying for a Master of Professional Practice.

(D) https://orcid.org/0000-0003-2394-9/31

\section{REFERENCES}

Andresen, L., Boud, D., \& Cohen, R. (1995). Experience-based learning. In G. Foley (Ed.), Understanding adult education and training (pp. 207-219). Allen \& Unwin.

Bennis, W. G. (1976). Why leaders can't lead. Soundview Executive Book Summaries. https://www.summary.com/booksummaries/_Why-Leaders-Cant-Lead

Bolton, G. (2010). Reflective practice: Writing and professional development (3rd ed.). Sage.

Butcher, A., \& McGrath, T. (2004). International students in New Zealand: Needs and responses. International Education Journal, 5(4), 540-551.

Clifford, A. (2018, April 27). On a mission to share New Zealand's food story. Eat New Zealand. https://www.eatnewzealand.nz/ food-stories/on-a-mission-to-share-new-zealands-food-story

Hardy, A., \& Whaanga, H. (2019). Using the stars to indigenize the public sphere: Matariki over New Zealand. Religions, I0(7), 431. https://doi.org/I0.3390/rell007043।

Helyer, R. (2015). Learning through reflection: The critical role of reflection in work-based learning. Journal of Work-Applied Management, 7(I), 15-27. https://doi.org/I0.1108/JWAM-10-2015-003

Johnson, W. (2012, February 17). Symbiosis: Teachers and students. Schools and Ecosystems: Socio-ecological perspectives on education. https://schoolecosystem.org/2012/02/17/symbiosis-teachers-and-students.

Kolb, D. (1984). Experiential learning: Experience as the source of learning and development. Prentice-Hall.

Larrivee, B. (2000). Transforming teaching practice: Becoming the critically reflective teacher. Reflective Practice, I(3), $293-307$. https://doi.org/10.1080/713693162

Rogers, C. (1969). Freedom to learn. Charles E. Merrill.

Rogers, C. (1983). The interpersonal relationship in the facilitation of learning. In C. Rogers, Freedom to learn for the 80's (pp. 119-134). Charles E. Merrill. 
Te Kete Ipurangi. (n.d.). Tuakana-teina: The concept of a tuakana-teina relationship. https://tereomaori.tki.org.nz/Curriculumguidelines/Teaching-and-learning-te-reo-Maori/Aspects-of-planning/The-concept-of-a-tuakana-teina-relationship

Toi Ohomai institute of Technology. (2021, April 27). About us. https://www.toiohomai.ac.nz/about

Vaughan, K. (2012). The integration of work and learning in New Zealand: A working paper. New Zealand Council for Educational Research.

Winitana, M. (n.d.). Remembering the deeds of Māui: What messages are in the tuakana-teina pedagogy for tertiary educators? Mai: A New Zealand Journal of Indigenous Scholarship, I(I), I-9. http://www.journal.mai.ac.nz/content/remembering-deedsm\%C4\%8lui-what-messages-are-tuakana-\%E2\%80\%93teina-pedagogy-tertiary-educators

Woodward. (2020, November 20). Maori proverbs: Whakataukī. Woodward Maori. https://www.maori.cl/Proverbs.htm 